\title{
On Molecular Mechanisms Guiding Embryonic Mammary Gland Development
}

\author{
Gertraud W. Robinson \\ Laboratory of Genetics and Physiology, National Institute of Diabetes and Digestive and Kidney Diseases, \\ National Institutes of Health, Bethesda, Maryland 20892 \\ Correspondence: gertraur@bdg10.niddk.nih.gov
}

$\mathrm{T}_{\mathrm{n}}^{\mathrm{h}}$ he major part of mammary gland development takes place in the adult and is strictly controlled by hormones. Ovarian steroid production starts during puberty and initiates outgrowth of a ductal system and pregnancy hormones induce the formation of alveoli that consist of secretory cells that produce milk to nourish the young. Yet, mammary development begins in the embryo, and newborn pups have a small ductal system that originates at the nipple. In contrast to the adult, the embryonic period of development is not orchestrated by systemic hormonal cues. The signals that regulate embryonic mammary epithelial development act more locally and rather, reflect the embryological origin of the gland as an appendage of the epidermis. In fact, many of the signals are also used as regulators of teeth and hair follicles, as well as other apocrine glands. Cowin and Wysolmerski (2011) provide an up-to-date overview of the current state of our understanding of these signaling events. These encompass the initiation of the milk line, an area along the ventral body wall where ectodermal cells are receptive to signals that induce the formation of distinct mammary epithelial placodes in specific locations, the formation of epithelial buds and specialized mammary mesenchymal cells, and finally, the outgrowth and branching of ducts.

Much of our knowledge about these events has come from natural mutants in mice and humans and the identification of the underly- ing mutations, as well as genetic experiments using targeted loss and gain of function in mice. In fact, the discovery that deletion of the gene encoding the transcription factor LEF1, a mediator of WNT signals, causes a block in the development of mammary buds provided a first inroad into a molecular analysis. An unexpected disruption of proper mammary bud development also occurs in mutants that primarily affect somite and skeletal development in the human ulnar-mammary syndrome, which is attributable to a mutation of the transcription factor TBX3. Thus, it appears that skeletal signals in collaboration with additional signals coming from the lateral mesenchyme provide the positional information for the formation of the milk line by creating gradients of growth factors such as fibroblast growth factors (FGFs), WNTs, bone morphogenetic proteins (BMPs), and NRG3. These factors induce the localized expression of epithelial transcription factors TBX3 and LEF1 and initiate morphogenetic movements that result in the formation of an epithelial bud. As the investigators point out, the mechanisms that underlie these morphogenetic events that most likely involve alterations of cell adhesion and motility are completely unexplored. Once epithelial identity is defined, the epithelial cells secrete a shortrange signal, PTHrP, which influences the fate of the abutting dermal mesenchyme. In response, the mesenchymal cells form a dense

Editors: Mina J. Bissell, Kornelia Polyak, and Jeffrey M. Rosen

Additional Perspectives on The Mammary Gland as an Experimental Model available at www.cshperspectives.org

Copyright (C) 2012 Cold Spring Harbor Laboratory Press; all rights reserved; doi: 10.1101/cshperspect.a013524

Cite this article as Cold Spring Harb Perspect Biol 2012;4:a013524 
G.W. Robinson

sheath of fibroblastlike cells surrounding the bud. Misexpression of PTHrP in the epidermis of transgenic animals showed that in a reciprocal interaction with adjacent epithelium these cells prevent formation of hair follicles in the ventral epidermis. It is tempting to speculate that the function of these cells is to shield mammary epithelial cells from more widespread ectodermal signals such as hedgehog and ectodysplasin, which induce hair follicle formation. This may ensure maintenance of mammary epithelial identity and prevent the cells from reverting to an epidermal fate. At a slightly later stage, PTHrP stimulates cell proliferation and forces the epithelial bud to elongate and grow to form a primary duct that pushes through the surrounding mammary mesenchyme into deeper layers of the dermis, where it associates with cells that are destined to form a fat pad. The interaction with the fat pad supports ductal outgrowth and epithelial branching during all subsequent development into the adult stages.

One intriguing question concerns the exact nature of the epithelial cells in the mammary anlagen. Can they be considered stem cells because they are the precursors to all the cell types in the adult gland? In the adult ductal system stem cells have been shown to be devoid of receptors for steroid hormones and they are thought to be regulated by paracrine signals from neighboring cells. Expression of progesterone receptors has been detected in mammary rudiments in the mouse (Ismail et al. 2002). It also has been shown that the epithelial cells in the early bud display uniform expression of a stem cell-specific promoter and that this expression becomes restricted to cells at the periphery once the primary duct has formed (Rohrschneider et al. 2005). This might indicate the formation of a paracrine-signaling network between divergent cell types, some of which assume stem cell character. A recent publication showed that WNT signals regulate self-renewal of adult mammary stem cells (Zang and Nusse 2010). As pointed out above, WNTs also prominently regulate early stages of mammary development.

One recurring theme in the embryonic phase is that some signals exert different functions at different stages, indicating that they act in a cellspecific context that may be determined by the availability of receptors and transcription factors, which mediate the extracellular responses. Deciphering the molecular details of these will be one of the challenges for future research.

\section{REFERENCES}

${ }^{*}$ Reference is also in this collection.

* Cowin P, Wysolmerski J. 2011. Molecular mechanisms guiding embryonic mammary gland development. Cold Spring Harb Perspect Biol doi: 10.1101/cshperspect. a003251.

Ismail PM, Li J, DeMayo FJ, O’Malley BW, Lydon JP. 2002. A novel LacZ reporter mouse reveals complex regulation of the progesterone receptor promoter during mammary gland development. Mol Endocrinol 16: 2475-2489.

Rohrschneider LR, Custodio JM, Anderson TA, Miller CP, $\mathrm{Gu}$ H. 2005. The intron 5/6 promoter of the shipl gene regulates expression in stem/progenitor cells of the mouse embryo. Dev Biol 283: 503-521.

Zeng YA, Nusse R. 2010. Wnt proteins are self-renewal factors for mammary stem cells and promote their longterm expansion in culture. Cell Stem Cell 6: 568-577. 


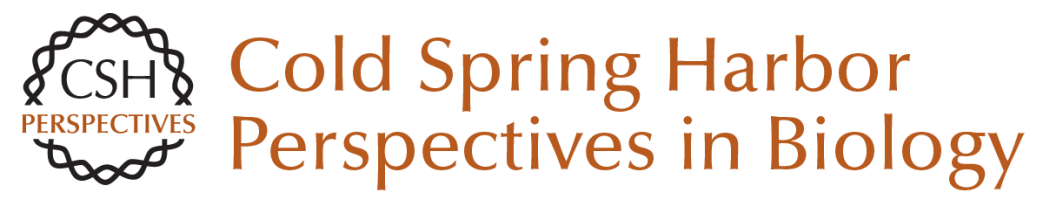

\section{On Molecular Mechanisms Guiding Embryonic Mammary Gland Development}

Gertraud W. Robinson

Cold Spring Harb Perspect Biol 2012; doi: 10.1101/cshperspect.a013524

Subject Collection The Mammary Gland as an Experimental Model

On the Role of the Microenvironment in Mammary Gland Development and Cancer

Derek Radisky

On Using Functional Genetics to Understand

Breast Cancer Biology

Kornelia Polyak

On Oncogenes and Tumor Suppressor Genes in the Mammary Gland

Rushika M. Perera and Nabeel Bardeesy

On Leukocytes in Mammary Development and

Cancer Cyrus M. Ghajar

On Chromatin Remodeling in Mammary Gland

Differentiation and Breast Tumorigenesis Kornelia Polyak

On Hormone Action in the Mammary Gland J.M. Rosen

TGF- $\beta$ Biology in Mammary Development and Breast Cancer

Harold Moses and Mary Helen Barcellos-Hoff
On How Mammary Gland Reprogramming

Metalloproteinases Couple Form with Function Bonnie F. Sloane

On Molecular Mechanisms Guiding Embryonic Mammary Gland Development Gertraud W. Robinson

On Stem Cells in the Human Breast Mark A. LaBarge

On Murine Mammary Epithelial Stem Cells:

Discovery, Function, and Current Status Jeffrey M. Rosen

On In Vivo Imaging in Cancer David Piwnica-Worms

Choosing a Mouse Model: Experimental Biology in Context--The Utility and Limitations of Mouse Models of Breast Cancer Alexander D. Borowsky

Mammary Gland ECM Remodeling, Stiffness, and Mechanosignaling in Normal Development and Tumor Progression

Pepper Schedin and Patricia J. Keely

For additional articles in this collection, see http://cshperspectives.cshlp.org/cgi/collection/

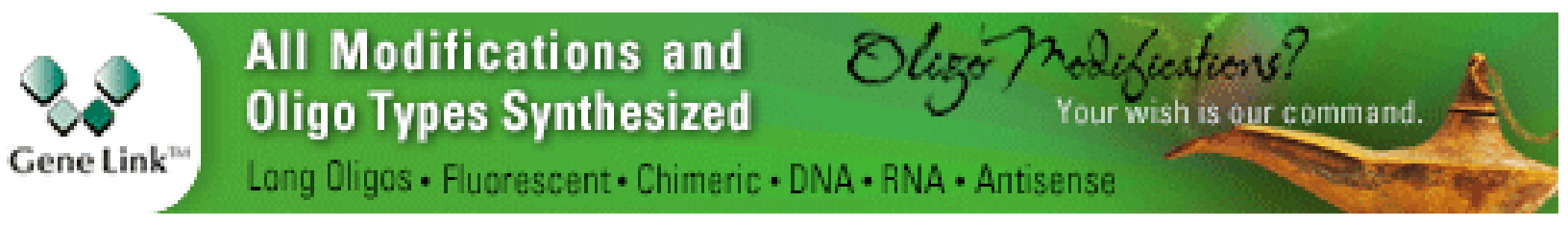

Copyright @ 2012 Cold Spring Harbor Laboratory Press; all rights reserved 
A Compendium of the Mouse Mammary Tumor Biologist: From the Initial Observations in the House Mouse to the Development of Genetically Engineered Mice

Robert D. Cardiff and Nicholas Kenney
Molecular Mechanisms Guiding Embryonic Mammary Gland Development

Pamela Cowin and John Wysolmerski

For additional articles in this collection, see http://cshperspectives.cshlp.org/cgi/collection/

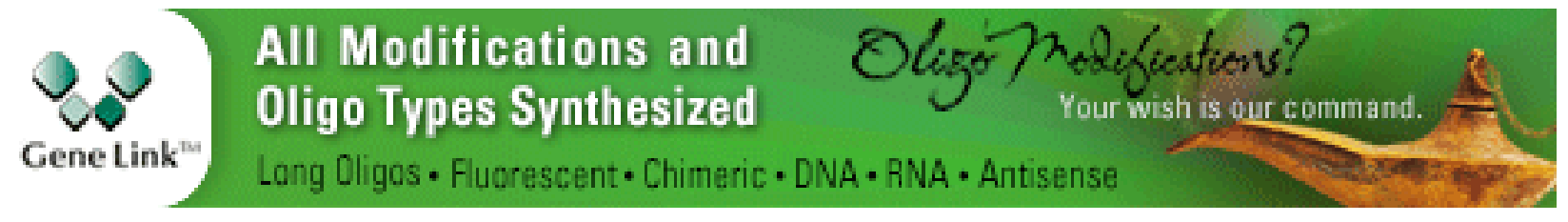

Copyright @ 2012 Cold Spring Harbor Laboratory Press; all rights reserved 